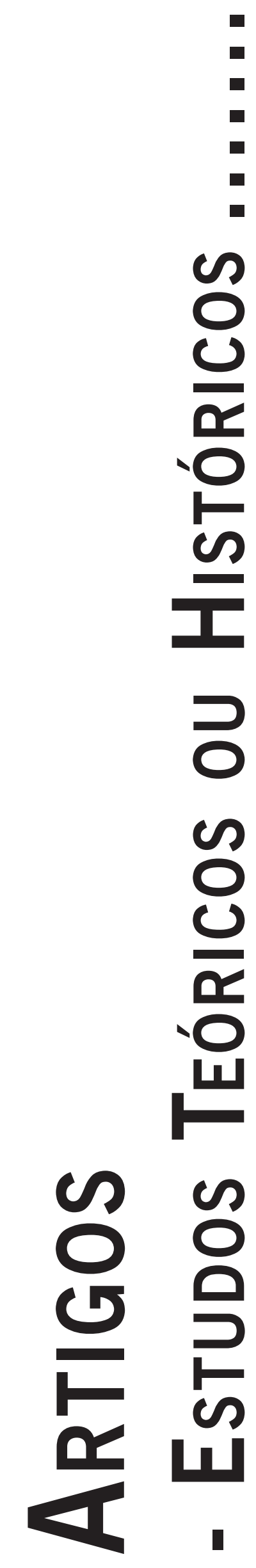




\title{
JOHN KEITH WOOD E A ABORDAGEM CENTRADA NA PESSOA NO BRASIL
}

\author{
John Keith Wood and the Person-Centered Approach in Brazil \\ John Keith Wood y el Enfoque Centrado en Persona en Brasil
}

VIRGINIA MOREIRA

Liane BASTOS LANDIM

Geórgia Silva Romcy

\begin{abstract}
Resumo: Este artigo tem como objetivo expor as contribuições de John Keith Wood para a Abordagem Centrada na Pessoa (ACP) no Brasil, a partir dos seus trabalhos com a ACP desenvolvida por Carl Ransom Rogers. Trabalhamos com o seu material bibliográfico publicado na área e com entrevistas realizadas com Lucila Assumpção, viúva de John Wood, e Vera Cury, ex-aluna e sua amiga. Concluímos que a vida e a obra de John Wood estão totalmente entrelaçadas, e que não é possível compreender uma sem a outra. Quanto às suas principais contribuições, consideramos que sua perspectiva de trabalho com grupos teve sempre como pano de fundo uma visão holística, imparcial, ambígua e humana. John Keith Wood pode ser considerado, além de um desmistificador da abordagem, um dos sucessores de Carl Rogers que mais desenvolveram as possibilidades de construção e aplicação da ACP. Palavras-chave: Psicologia humanista; Abordagem centrada na pessoa; Carl Rogers; John Wood.
\end{abstract}

\begin{abstract}
This article aims to expose the contributions of John Keith Wood to Person-Centered Approach (PCA) in Brazil, having as start point his work with the PCA developed by Carl Ransom Rogers. We worked based on John Wood's scientific publications and interviews conducted with Lucila Assumpção, John’s widower, and Vera Cury, his student and great friend. We came to the conclusion that John Wood's life and work are fully weaved, and that it is not possible to understand one without referring to the other. His main contributions refer to his work with groups, whose functioning has, as its background, the development of a holistic, impartial, ambiguous, and humanistic perspective. John Keith Wood can be considered a demystifier of the approach and one of the successors of Rogers that most developed possibilities for the implementations of the PCA.

Keywords: Humanistic psychology; Person-centered approach; Carl Rogers; John Wood.

Resumen: este artículo pretende explicar las aportaciones de John Wood Keith en el Enfoque Centrado en Persona (ECP) en Brasil a partir de sus trabajos con el enfoque centrado en persona (ECP) desenrollado por Carl Ransom Rogers. Trabajamos con su material bibliográfico publicado en el área y entrevistas con Lucila Assumpção, viuda de John Wood y Vera Cury, su ex alumna y amiga. Concluimos, entonces, que la vida y obra de John Wood están totalmente entrelazadas y que no se puede entender una sin la otra. En relación a sus importantes contribuciones, consideramos que su perspectiva de trabajar con grupos siempre tuvo como telón de fondo un enfoque integral, imparcial, ambiguo y humano. John Keith Wood puede ser considerado además de un desmitificador del enfoque, uno de los sucesores de Rogers que más desarrollaron posibilidades para la construcción y práctica del ECP. Palabras-clave: Psicología humanista; Enfoque centrado en la persona; Carl Rogers; John Wood.
\end{abstract}

\section{Introdução}

A psicologia humanista no Brasil desenvolveu-se como uma terceira força da psicologia em oposição à psicanálise e à psicologia comportamental, teorias vigentes na época, sendo uma proposta diferente no que se refere ao determinismo dicotômico, ao mecanicismo e ao reducionismo dessas duas outras teorias, com "uma visão globalizante do ser humano, que enfatiza a vivência das emoções" (Moreira, 2009, p. 26). Moreira (2010b, p. 39) destaca que "do ponto de vista histórico um dos momentos que marca o nascimento da psicologia humanista é o Simpósio de Psicologia Existencial organizado por Rollo May em 1959, contando com a presença de Maslow,
Allport e Rogers, entre outras personalidades”, todos eles futuros condutores do movimento humanista pelo mundo. Destacamos como abordagens representantes da psicologia humanista: a Gestalt-Terapia, a Abordagem Centrada na Pessoa e a Logoterapia, teorizadas por Fritz Perls, Carl Rogers, Viktor Frankl, respectivamente, entre outros autores (Gomes, Holanda e Gauer, 2004).

A Abordagem Centrada na Pessoa (ACP), desenvolvida por Carl Ransom Rogers, contou com a colaboração preciosa de John Keith Wood, além de outros colaboradores, como Maureen Miller O’Hara e Maria Bowen, que visitaram o Brasil na década de 1970, todos integrantes da equipe de Rogers no Center for Studies of the Person, em La Jolla, na Califórnia, do qual ele era membro fundador 
e supervisor. Os participantes deste grupo não somente assistiram, mas, também, participaram efetivamente do desenvolvimento das ideias dessa corrente teórica, além de estabelecerem um envolvimento pessoal com Rogers, tornando-se amigos próximos. Realizaram diversos programas de formação de psicoterapeutas e facilitadores de grupos, além de promoverem workshops em países da América do Norte, América do Sul, Europa e Pacífico (Gomes, Holanda \& Gauer, 2004; Wood, 2008a, 2008b).

Foi através do empenho de Eduardo Bandeira que Carl Rogers e sua equipe do Instituto La Jolla vieram ao Brasil e empreenderam seus primeiros trabalhos com grupos vivenciais, em 1977, com a realização dos Ciclos de Estudo da Pessoa, em Recife, Rio de Janeiro e São Paulo, tendo como objetivo propagar e desenvolver a aplicabilidade da ACP. Esta primeira visita foi finalizada com o primeiro grupo vivencial realizado por eles, aqui no Brasil, na Aldeia do Arcozelo, em uma serra do Rio de Janeiro, contando com a participação de aproximadamente 800 pessoas (Gomes, Holanda \& Gauer, 2004; Bandeira, 2012). Este encontro, com duração de três semanas, foi realizado de forma não-diretiva: "não havia nem pauta, e a comunidade foi planejando e realizando as atividades, debatendo exaustivamente cada questão" (Gomes, Holanda \& Gauer, 2004 p.111). Bandeira (2012, p. 87) relata que "nosso foco eram as relações interpessoais e grupais: esse é o diferencial da ACP”. Este primeiro encontro centrado na pessoa rompeu com os moldes dos encontros científicos formais, orientando suas atividades para as pessoas e suas questões. Após esta visita, Rogers ainda retornou ao Brasil em 1978 e em 1985 para a realização de palestras e workshops (Gomes, Holanda \& Gauer, 2004; Bandeira, 2012).

Em meados da década de 1980, John Keith Wood passou a residir no Brasil. Aqui, "os seus feitos estão lado a lado com os da Dra. Rachel Léa Rosenberg, professora da Universidade de São Paulo” (Cavalcante Jr., 2008, p. 530). Ele, que era "um dos colaboradores mais próximos de Rogers” (Moreira, 2010a, p. 538), passou a ter um papel importante para a ACP neste país. Sua contribuição à psicologia humanista no Brasil foi de tal magnitude e importância que foi homenageado no XII Fórum Internacional da Abordagem Centrada na Pessoa e no X Fórum Brasileiro da Abordagem Centrada na Pessoa, realizados, concomitantemente, em maio de 2013, na praia do Cumbuco, no Ceará.

Para a realização deste artigo, nós utilizamos as obras publicadas por John Wood, os seus escritos sobre a ACP e entrevistas realizadas em 2012 com Lucila Assumpção, sua esposa e companheira até seus últimos dias, e com Vera Engler Cury, aluna no curso de formação e sua amiga por muitos anos. Neste trabalho, discorreremos sobre o entrelaçamento da sua vida e obra, nunca esquecendo seu profundo interesse pelas relações interpessoais. Este trabalho tem como objetivo descrever as contribuições de John Keith Wood para a Abordagem Centrada na Pessoa (ACP) no Brasil, explicitando sua inserção neste campo de saber, apresentando suas publicações e enfocando suas principais contribuições.

\section{John Keith Wood: biografia e personalidade}

John Keith Wood nasceu nos Estados Unidos, em 1934. Seu pai era artífice e, quando criança, o filho gostava de acompanhá-lo nos seus trabalhos. Na infância, apreciava despertar sob o som dos trens distantes, o que lhe causava uma gostosa saudade (Wood, 1985). Conforme o relato de Vera (Cury)1, "John falava que ele era de Los Angeles e que como menino de Los Angeles ele tinha vivido toda aquela fase de um adolescente rebelde, essas coisas, mas ele era classe média, ele precisou trabalhar pra estudar". Sobre essa atitude rebelde, o próprio Wood (1985, p. 104) a descreveu, apontando sua vontade de usar "cabelo estilo marginais da época: bem compridos atrás e penteados num rabo-de-pato”. Apesar desse comportamento e de ter crescido numa cidade cosmopolita, Vera frisa que ele era tímido, não tendo muita facilidade de estar no meio social como "rei" da cena, como muitos pensavam acerca dele. Ela conta, ainda, que John Wood gostava de viver de maneira saudável, não tendo interesse em drogas ou fumo, tomando apenas algumas poucas cervejas.

Casou-se, pela primeira vez, com uma americana, mãe de seu único filho, Stanton Evan Wood, ficando viúvo quando seu filho tinha cerca de 12 anos. Sobre o falecimento da primeira esposa, sabemos que foi um momento de profunda angústia e raiva, pela morte prematura e por não poderem desfrutar de uma longa e saudável vida juntos (Wood, 1985). Conforme relato de Vera, ele teve outra companheira durante o período em que trabalhou com Rogers no Instituto La Jolla. No início da década de 1980, quando veio ao Brasil para a realização de um workshop, organizado por Raquel Rosenberg e sua equipe da USP, em Vinhedo, São Paulo, conheceu Lucila Assumpção, uma das participantes deste grupo e, mais tarde, sua companheira até os últimos dias. Depois de Vinhedo, John Wood foi a Fortaleza, a convite de Virginia Moreira. Esta já era a sua segunda visita a Fortaleza: a primeira, cerca de dois anos antes, havia sido, também, para facilitar um grupo vivencial que aconteceu na serra de Baturité, a convite de Gercileni Araújo e Afonso Fonseca. Decorrido algum tempo de idas e vindas entre Brasil e Estados Unidos, John e Lucila casaram-se, em 1985, para que ele pudesse receber seu visto permanente para residir no Brasil. Aqui, estabeleceu residência na cidade de Jaguariúna, no Estado de São Paulo, na Estância Jatobá, local que se tornou um grande projeto do casal, e onde, ainda hoje, vive Lucila. Como já havia sido professor da Universidade Estadual de San Diego, na Califórnia, buscou continuar suas atividades acadêmicas no Brasil, tendo sido professor da Pós-Graduação em Psicologia da Pontifícia Universidade

\footnotetext{
A partir desse momento, iremos nos referir à entrevista com Vera Cury apenas através do primeiro nome, Vera.
} 
Católica (PUC) de Campinas, São Paulo, durante cinco anos. Sobre este período, Lucila (Assumpção) ${ }^{2}$ aponta sua dificuldade com a língua portuguesa, fazendo com que ela o auxiliasse como tradutora das suas aulas. Em decorrência disto, por vezes, ele sentia-se incompreendido, pois sua dificuldade de expressar-se em outra língua, que não o inglês, fazia com que ele parecesse não dominar o que sabia.

Apreciava jogar basquete, e, mais tarde, o casal aderiu ao jogo de tênis. Era um praticante disciplinado de meditação e um leitor assíduo de sufismo. John Keith Wood faleceu em 22 de agosto de 2004, em decorrência de uma hepatite $\mathrm{C}$, tardiamente diagnosticada, possivelmente contraída em uma viagem feita à Índia.

Tanto Lucila quanto Vera lembram que John Wood gostava de dizer que teve três profissões: iniciou como engenheiro, seguindo para a psicologia e, nos seus últimos anos, dedicando-se ao ambientalismo e a tudo o que estivesse associado à natureza. Embora essas profissões sejam diferentes, a partir da sua história, é possível perceber como elas se articulam e se entrelaçam, gerando frutos no seu pensamento. Vera acredita que as primeiras formações acadêmicas de John Wood, por não terem sido no campo da Psicologia, contribuíram para a sua visão e seu manejo profissional, pois, em suas palavras, "o John trouxe esse lado mais pragmático, mais operacional, pro trabalho dele da abordagem", o qual lhe permitiu não se impregnar de um pensamento meramente psicológico, mas voltado à resolução dos problemas que emergem.

Homem de uma honestidade e integridade profunda, Vera acredita que "ele tinha essa sensação muito forte de que ele deveria ir a lugares em que sentisse que poderia ser útil, e onde as pessoas estivessem interessadas no que ele tinha a dizer, e não ser uma presença simbólica", como acabava acontecendo em convites em que ele era tratado como uma celebridade, já que se sentia extremamente irritado, pois pareciam ser situações manipuladas para que ele fosse apenas como presença, não para ser ouvido. Fonseca (2012), em texto publicado na internet, acrescenta que ele era amigável, intuitivo, bem-humorado, inteligente, perspicaz, possuidor de um jeito particular de pensar e abordar a realidade, de uma originalidade muito grande e com um humor fino.

\section{Da NASA à psicologia: a mudança de carreira de John Wood}

Quando John Wood iniciou seus artigos sobre a ACP, esclareceu, desde logo, que, para ele, esta abordagem não se originou de estudos teóricos seriamente investigados, mas de uma vivência real e prática (Wood, 2008). Na sua função de engenheiro aeroespacial dedicado a desenhos para a NASA - seu trabalho anterior à Psicologia, em

\footnotetext{
A partir desse momento, iremos nos referir à entrevista com Lucila Assumpção apenas através do primeiro nome, Lucila.
}

virtude dos problemas econômicos pelos quais passava os Estados Unidos -, John Wood trabalhou num projeto do governo norte-americano de geração de empregos, aproximando-se, assim, da psicologia. Em 1970, passou a fazer parte da equipe de Carl Rogers no Center for Studies of the Person do Instituto La Jolla, na Califórnia, Estados Unidos.

Sobre o título de Ph.D. de John Wood em Psicologia, em 1973, Lucila informa que ele desenvolveu a tese The Joy of Being Fired: facilitating the life-transitions of displaced persons, sobre engenheiros e suas questões psicológicas. Conforme Vera, neste projeto de recolocação profissional do governo americano, John Wood teve acesso às experiências desses trabalhadores desempregados, já que não conseguiam se realocar no mercado de trabalho por causa de suas altas qualificações. Nesta experiência, as pessoas se reuniram em um local de encontro e, discutindo entre si, encontraram soluções pessoais muito interessantes para suas vidas, expondo a importância do processo grupal para cada um deles. Esses encontros foram profundamente marcantes e decisivos para os beneficiados e para o próprio John Wood, que, a partir daí, mudou de carreira. As reflexões a partir das atitudes do grupo marcaram o despertar do seu interesse pela psicologia e, especialmente, pelos trabalhos de grupo, empenho que se manteve presente ao longo de toda a sua trajetória na abordagem centrada na pessoa. Seu trabalho sobre a compreensão dos processos e da facilitação de grupos foi, sem dúvida, seu grande ensinamento a toda uma geração de psicoterapeutas e psicólogos brasileiros que tiveram o privilégio de conviver com ele, aprendendo sobre este tema e vivenciando esta abordagem.

\section{O legado teórico de John Wood}

John Wood se empenhou arduamente em diversos trabalhos com o objetivo de ajudar a esclarecer o papel da ACP. É autor de mais de 35 publicações e quatro li$\operatorname{vros}^{3}$, segundo informações de um site na internet, escrito por Lucila Assumpção. Em português, encontramos: Em busca de Vida: da terapia centrada no cliente à abordagem centrada na pessoa, publicado em 1983, pela editora Summus, com capítulos dele, Carl Rogers, Maureen Miller O'Hara e Afonso H. L. da Fonseca; Vestígios de Espanto: notas de fim de semana de um psicólogo, publicado em 1985, pela editora Ágora, com tradução de Afonso Fonseca; Abordagem Centrada na Pessoa, que está dividido em duas partes, a primeira contando com a tradução dos artigos seminais de Carl Rogers por Jaime Doxsey, Lucila Assumpção, Márcia Tassinari, Marisa Japur, Mônica Serra, Raquel Wrona, Sonia Loureiro e Vera Cury, e a segunda, de autoria exclusiva de John Wood; e Cartas ao Hemisfério Norte, de autoria dele e

\footnotetext{
Informação retirada do site www.lumiajoy.com.br.
} 
de Lucila Assumpção, publicado em 2005, pela editora Komedi, além da publicação póstuma de uma obra em inglês, não traduzida, intitulada de Carl Rogers' PersonCentered Approach: toward an understanding of its implications, da autoria de John Wood, e publicada em 2008, pela PCCS BOOKS.

Na introdução de sua parte do livro Em busca de vida, John Wood deixa claro que seus escritos giram em torno do indivíduo e do grupo, escrevendo que

(...) os textos que se seguem ("Sombras da Entrega", "Terapia de grupo centrada na pessoa” e "Não se presume que um grupo faça você se sentir bem?”) representam três tentativas independentes de extrair e organizar o conhecimento derivado de experiências com abordagem centrada na pessoa aplicada a encontros de grupo e à psicoterapia (Wood, 1983, p. 21).

Em Vestígios de Espanto, John Wood discute sobre o que é o ser humano, afirmando, inclusive, que "o foco deste (livro) escapa de como o homem deveria ser, para como o homem é" (Wood, 1985, p. 13). Nesta obra, ele conta suas próprias histórias, bem como anedotas, ensaios, observações, notícias de jornais e reflexões suas e dos outros colegas, todas voltadas para como são os seres humanos. O livro está dividido em três partes: Notas sobre a Natureza Humana; Notas Profissionais; e Temas de Vida e Morte, Sonhos e Possibilidade, na qual ele busca, em pequenos textos, em sua maioria, discutir as relações dos sujeitos com suas situações cotidianas.

A obra Abordagem Centrada na Pessoa tem o objetivo de "alargar, iluminar e tornar mais útil uma compreensão não somente desse assunto, mas também ajudar a clarear a questão básica - Como se tornar um ser humano?” (Wood, 2008, p. 23-24). Foi elaborado com a contribuição de seus colegas interessados na Abordagem Centrada na Pessoa e conta com a re-tradução de seis artigos seminais de Rogers que representam as suas ideias fundamentais sobre psicoterapia. John Wood (2008) destacava que Rogers tinha a expectativa de que a teoria fosse reformulada com o tempo, pensada amplamente, dando uma organização cada vez mais coerente a seu pensamento, e que, quando ele percebeu que isso não estava acontecendo, empenhou-se no projeto desta obra, estimulando "uma reflexão sistemática sobre a evolução da Abordagem Centrada na Pessoa” (Wood, 2008, p. 23).

Conforme as palavras de Maureen O’Hara, no prefácio do livro Carl Rogers' Person-Centered Approach, "os artigos coletados aqui oferecem uma oportunidade de se engajar mais uma vez num diálogo (com John Wood), de participar no seu processo criativo, de experienciar sua coragem intelectual e imaginação poética”4 (O’Hara, 2008,

\footnotetext{
Tradução livre dos autores do artigo: "The essays that have been collected here provide an opportunity to engage in dialogue with him once more, to participate in his creative process, to experience his intellectual courage and poetic imagination".
}

p. vi). Esta obra é uma discussão das principais ideias desenvolvidas por Rogers, a partir da experiência com John Wood e com todo o grupo do Instituto La Jolla. Os capítulos oferecem uma discussão crítica baseada nos fatos, como apregoava Rogers, estimulando a compreensão dos fenômenos que se passam em psicoterapia. Wood (2008b) expõe nesse livro questões sobre as diferenças e as semelhanças que existem na psicoterapia centrada no cliente, na liderança centrada no cliente, no ensino centrado no cliente. Articula, então, as concepções que os unem enquanto Abordagem Centrada na Pessoa, e as divergências que os diferenciam nos seus campos de aplicações.

Wood (2008b) entende que o psicoterapeuta, trabalhando na abordagem rogeriana, convoca o máximo de consciência reflexiva, sensível, canalizada e disciplinada, comunicando-a na relação psicoterapêutica como uma forma de engajamento que exige tudo que o psicoterapeuta tem de melhor, na direção do melhor do cliente, otimizando as possibilidades de resultar no melhor que possa acontecer em um relacionamento. Para ele, falar sobre isso é bem mais simples do que praticar. Wood dedica quatro capítulos desta obra para teorizar sobre os trabalhos de grupo. Ele entende o grupo como uma orquestra, na qual cada participante toca sua sinfonia, mas que está sempre ecoando com a dos outros participantes, formando uma melodia. Cada grupo é um sistema com sua própria estrutura, mas, também, com liberdade, com criatividade, sem simulações, demonstrações e nem precipitações, mas organizando-se em torno de suas necessidades. Os papéis dos participantes vão se construindo, e não são somente os facilitadores que operam, suportam e ajudam, mas os próprios participantes começam a perceber a importância de usar o corpo e as emoções como forma de aprendizagem e de resolução dos problemas.

\section{Uma abordagem para a vida: contribuições de John Wood para a abordagem centrada na pessoa no Brasil}

John Wood aprendeu com Rogers que é na relação estabelecida entre cliente e psicoterapeuta que se encontra a eficácia do processo psicoterapêutico, e não na teoria, enfatizando o rompimento epistemológico decisivo com a tendência das outras abordagens da época, a psicanálise, e seu olhar para o inconsciente, e a análise do comportamento, e seu foco no comportamento: a abordagem centrada na pessoa deixava de analisar e diagnosticar para se interessar na ajuda efetiva ao paciente. Esta vertente, a ACP, entende que a ajuda não depende unicamente de elaborações teóricas e de diagnósticos refinados, e passa a incluir a cultura como um aspecto extremamente importante. Assim, Wood (1985, p. 75) pontua a importância de que, "apesar das inúmeras abordagens em psicoterapia, existem evidências de que a pessoa do terapeuta é mais importante do que sua técnica ou do que sua linha 
teórica”, focando, assim, na relação compartilhada entre psicoterapeuta e cliente. Nesta perspectiva, Moreira (2010a, p. 538) aponta que o psicoterapeuta "renuncia ao papel de especialista, tornando mais pessoais as relações com o cliente e conduzindo a sessão a partir da orientação ditada por este último”. Wood (1983) lembra que o psicoterapeuta tem que ser capaz de comunicar as condições psicoterapêuticas de genuinidade com empatia e não-avaliação, durante seus atendimentos ao cliente, para, então, poder considerar sua atuação como uma psicoterapia efetiva. Assim, a ACP é compreendida não apenas como uma teoria, mas como uma nova forma de ser no mundo, sem regras prévias, desvinculando-se de como as coisas deveriam ser para tentar enxergar como elas são, na realidade. Wood (2008a, p. 244) afirma que

(...) a Terapia Centrada no Cliente contribuiu para a prática da psicoterapia onde a teoria era deixada na entrada do consultório, onde somente a sinceridade, o espírito de descoberta e a criatividade são convidados a entrar; somente a mudança construtiva se espera que saia.

Ele enfatiza que não são apenas as condições do psicoterapeuta e nem a motivação interna do cliente que promovem o caráter psicoterapêutico da abordagem, fugindo da relação dual e de causa-efeito que estas ideias poderiam representar. Além de entender que é na relação estabelecida entre os dois que se dá a ocorrência dos fenômenos psicoterapêuticos, destaca que essa compreensão desresponsabiliza um e outro, e que as condições facilitadoras não são apenas causa, mas, também, resultado desta relação. Para compreender o fenômeno da psicoterapia, não é possível separar o psicoterapeuta, o cliente e o fenômeno que eles compartilham (Wood, 2008a; Wood, 2008b).

Para Wood, a psicoterapia, na ACP, é entendida como uma relação interpessoal complexa, que não pode ser compreendida através de formas isoladas das condições facilitadoras, nem de seus elementos sociais, históricos, culturais, biológicos e individuais, dentre outros. Por compreender a teoria e a prática da ACP desta forma, ele retomou pesquisas bem fundamentadas, respondeu às críticas, promoveu um diálogo entre elas, propôs formas menos rígidas de entender a teoria, assumindo uma postura profundamente crítica. Empenhou-se em esclarecer, em muitos momentos, o caráter ambíguo da relação do homem com o mundo, parecendo ser esta uma de suas maiores contribuições. Ele defende a ideia de que "somos determinados pela cultura e livres para escolher; portanto, em contrapartida, também determinando a cultura" (Wood, 2008a, p. 183).

Dentre os seus esclarecimentos, é importante destacar o que ele pensava sobre as atitudes psicoterapêuticas propostas como facilitadoras por Rogers (1961/2001). Achava importante ressaltar que elas não deveriam se tornar regras de comportamento, com frases soltas como "seja você mesmo". Cury (2012) lembra que ele tinha a preocupação de que a abordagem não se tornasse algo ideológico, pois sabia que poderia haver o risco de transformá-la numa religião ou num dogma. O’Hara acrescenta que "John tinha uma forte aversão às tentativas de transformar as sutis implicações da realidade da abordagem centrada na pessoa em métodos fechados e regrados, ou teorias acabadas"5 (O’Hara, 2008, p. v). Neste texto, Maureen O’Hara se refere a ele como um desmistificador da ACP no sentido de impedir que ela se transformasse, também, em algo folclórico, com envolvimento meramente afetivo das pessoas. Neste papel de ajudar a compreender a real essência da ACP nas suas aplicações no âmbito da psicologia, afirma que se trata de conhecer o processo em que as verdades são percebidas, ajudando as pessoas a clarearem suas próprias verdades (Wood, 2008a; Wood, 2008b).

Quanto ao funcionamento pleno e individualizado do homem, John Wood ressalta que a compreensão dele deveria englobar esferas não apenas individuais, mas, também, coletivas, num intercâmbio ativo e dinâmico, enfatizando a relação de responsabilidade entre elas. Através dos seus trabalhos sobre grupos, percebemos sua preocupação maior com esta ideia. Wood (2008b) dizia que para Rogers o indivíduo era único, singular, e que tinha uma liberdade soberana. Ele discordava dessa idéia afirmando que "a rede de pensamentos, sentimentos, opiniões, conceitos, valores; a conexão biológica entre as pessoas influenciam a maneira como uma pessoa se expressa" (Wood, 2008a, p. 189).

Também é com seus trabalhos sobre grupos que John Wood desenvolve uma parte importante de suas publicações. Escreveu sobre grupos de duas pessoas, pequenos e grandes grupos, como ele mesmo descreve: "esta abordagem centrada na pessoa da psicoterapia de grupo (ainda que não negue a desordem), fundamenta-se nas naturais tendências da vida para a ordem" (Wood, 1983, p. 47). Na obra Em Busca da Vida, Wood (1983) discute sobre a seleção dos membros para os grupos, sua composição, seu tamanho, ambiente, frequência, periodicidade e duração das sessões, o material utilizado e o papel do psicoterapeuta. À exceção deste último ponto, os demais seguem a regra básica dos grupos, de que "não existem regras básicas estabelecidas para os grupos centrados na pessoa" (p. 68); portanto, essas questões variam de acordo com as características do grupo e de como ele se movimenta. O papel do psicoterapeuta, ou facilitador, é possibilitar a criação de um clima criativo, em que os participantes possam vivenciar a sua totalidade, seja pelo contato com o facilitador, com os membros do grupo e/ ou consigo mesmos (Wood, 1983). Aliás, acreditava que a vida e as relações estavam sempre permeadas por esta rede complexa, por tudo o que circunda o ser humano,

\footnotetext{
5 Tradução livre dos autores do artigo: "John had a strong aversion to any attempts to turn the subtle implicate reality of the person-centered approach into locked down, rule-bound methods or finished theories".
} 
pelas relações que o constituem, em grupos formais ou não, e, mesmo quando está sozinho, ou em um "grupo de dois", como gostava de chamar o processo psicoterapêutico individual, carregava esta percepção holística, quer como teórico, quer como facilitador, profissional e ser humano. Desde o seu trabalho de orientação profissional para o governo americano, no qual sua vocação para tal modo de perceber a vida começou a se delinear, passando pelo encontro entre ele e Lucila Assumpção, no grupo vivencial, em Vinhedo, no Brasil, no início dos anos 1980, até seu trabalho com a comunidade em Holambra, onde participou do desenvolvimento do plano diretor dessa cidade, principalmente, no que concerne a educação ambiental, no qual sua afinidade com a ACP tornou-se inegável. John Wood demonstrou que era assim que ele experimentava as suas relações e entendia que a abordagem centrada na pessoa era algo para além do setting psicoterapêutico.

Identificamos que o objetivo de John Wood foi, em muitos momentos, argumentar com as críticas recebidas pela teoria rogeriana, buscando explicar tanto o contexto em que as perspectivas da ACP foram desenvolvidas, quanto o lugar a partir do qual as críticas vieram, para, assim, estimular a criticidade e as possibilidades do diálogo. Fez isto, demonstrando o seu profundo compromisso de não cair em afirmações estáticas, frutos de críticas cegas que acabaram apregoando preconceitos e desvirtuando a essência das concepções, como aconteceu e ainda acontece com alguns seguidores da ACP (Wood, 2008a; Wood, 2008b). Portanto, sua compreensão é de que a ACP não é nem uma psicoterapia nem uma psicologia. Não é uma escola, como a comportamental ou a psicanalítica. Também não é um movimento. Mesmo que alguns tenham notado uma noção existencial nas suas atitudes e outros tenham percebido uma intuição na perspectiva fenomenológica, a ACP, também, não é uma filosofia. É uma abordagem para a vida e todas as formas de ser, e que pode estar presente na psicoterapia, na educação, nos grupos de encontro, nos workshops, ou seja, em tudo que diz respeito às relações humanas.

Nas suas atividades na Estância Jatobá, na região de Jaguariúna, em São Paulo, John Wood se dedicou à fazenda onde ele viveu com Lucila Assumpção, realizando estudos de permacultura ${ }^{6}$ e agroecologia, desenvolvendo atividades entre os agricultores regionais e trabalhando até mesmo com o plano diretor de Holambra, de onde foi diretor do conselho rural. Envolveu-se intensamente nesta comunidade, como fruto da educação ambiental holística, que tanto estudou e buscou implementar, o que nos permite conhecer um pouco sobre o seu profundo sentimento de responsabilização com questões ligadas ao ambiente e à ecologia. Em Wood (2008a), ele conta que

\footnotetext{
Permacultura é um método holístico para planejar, atualizar e manter sistemas de escala humana (jardins, vilas, aldeias e comunidades) ambientalmente sustentáveis, socialmente justos e financeiramente viáveis.
}

entendia responsabilidade ecológica como ação, ao invés de adoração, privilegiando o coletivo e o holismo, ao invés da cultura individualista e separatista, mas mantendo sempre a singularidade e a interação e mostrando a sua habilidade de perceber as partes, mas, também, os padrões do todo, como destacou L. Assumpção (2012). Cavalcante Junior (2008, p. 534) refere-se ao seu envolvimento neste local como sendo "sua estufa formativa". Em relação a este ponto, vale lembrar que Wood tinha uma abordagem mais abrangente acerca da compreensão holística do que a proposta rogeriana. A proposta de Rogers (1961/2001) sobre o holismo no processo psicoterapêutico restringia-se ao ambiente da sessão, focando-se apenas nas atitudes mantidas pelo terapeuta durante o processo com seu cliente.

Wood (2008b) considerava que o holismo iria além das condições estabelecidas entre o terapeuta e o cliente numa relação terapêutica, devendo abranger, por exemplo, o ambiente, nas suas características físicas, tais como o local, a decoração, o cheiro, o som e a claridade, e aspectos, como o social, o econômico, dentro outros. Essas perspectivas são bastante relevantes, mas não determinam a relação psicoterápica, são constituintes das repercussões na experiência, nos sentimentos e nos comportamentos dos parceiros desta relação. Assim, estendia a compreensão de ambiente à uma esfera mais ampla, a emocional. Nas palavras dele:

(...) a organização do ambiente pode facilitar uma pessoa a ter percepções para além de si mesma, refletir sua própria vida, a realizar seus verdadeiros desejos, conseguir insight sobre seus problemas pessoais, ou a chegar a novas percepções de seu relacionamento com a sociedade - o mesmo que se espera de uma boa psicoterapia (Wood, 2008a, p. 221).

Para John Wood, a pessoa consegue se reorganizar emocionalmente não apenas com um trabalho de psicoterapia, pois, já que não são meras atitudes do psicoterapeuta que operam este efeito, há ampliação das possibilidades de percepção quando se entende o todo que constitui esse sujeito de forma holística.

Wood (2008b) lembrava que Rogers (1961/2001) sempre acreditou no potencial positivo das pessoas. Assim sendo, por muito acreditarem nas condições da abordagem centrada na pessoa e nas suas atitudes facilitadoras, os terapeutas procuravam a presença delas o tempo inteiro na relação. Mas quando não viam as condições presentes, caíam no erro da moral e do julgamento. Ao buscar escutar uma profunda genuinidade do cliente e não a encontrarem, deixavam de escutar o que ele conseguia falar, mesmo que não genuíno. Neste contexto, Wood (2008b) discorre que o terapeuta deve ter uma função compreensiva, pois considerava a ambiguidade coexistente em todos os aspectos da natureza humana. Essa função fornece possibilidades para que cada um conheça essas am- 
bigüidades, como complementou este pensamento: "seres humanos reais possuem, igualmente, forças surpreendentes e fraquezas surpreendentes" (Wood, 1985, p. 13).

Neste sentido, a contribuição de Wood para a ACP é explicitada por Cury (2012), ao afirmar que ela

(...) foi ter recuperado os princípios norteadores da Abordagem Centrada na Pessoa de uma maneira lúcida, não deslumbrada, madura, consolidada pela experiência dele de vida, e acho que ele se sentia muito responsável em dar àquilo que o Rogers tinha produzido a justa medida, nem mais nem menos.

Moreira (2009, p. 27) destaca que alguns "autores da abordagem humanista não se preocupavam com os fundamentos teórico-epistemológicos de suas ideias, argumentando serem suas abordagens experienciais, ou seja, provenientes de sua própria experiência”. Esta foi, justamente, uma preocupação, também, de John Wood: de que a ACP não fosse transformada em uma ideologia, uma teoria que pudesse ser manejada de qualquer forma, pelo simples desejo do psicoterapeuta, sem a preocupação com seus fundamentos. Wood buscou deixar claro que a ACP é uma abordagem que tem fundamentação e que ela deve ser levada em consideração. Cavalcante Junior (2008, p. 535) ratifica esta ideia, ao afirmar que "essa era a grande esperança de John: manter a força e mobilidade da ACP, e seu potencial revolucionário, não apenas disponível, mas pronto para ser utilizado quando, novamente fosse requisitado". Suas obras, seus trabalhos e suas relações, lhe trouxeram o reconhecimento de ter sido alguém profundamente comprometido com a tarefa de ser humano. Amatuzzi et al. (2002) ratificam o mérito de John Wood de desmistificar que a abordagem centrada na pessoa (ACP) seja uma aplicação da terapia centrada no cliente (TCC) em outras situações. Segundo eles, "a ACP, enquanto uma abordagem dos problemas humanos, correspondia a princípios gerais que estavam por trás de uma forma de psicoterapia, a TCC, e que podiam também estar por trás do modo de agir em outros campos" (Amatuzzi et al., 2002, p. 6). Conforme Fonseca (1983, p. 142), John Wood afirmava que "a abordagem centrada na pessoa confia na potência das forças naturais da vida e esforça-se por estabelecer um clima que não interfira com seus propósitos". Certamente, esta é um dos princípios que John Wood aplicou em sua própria vida, como psicólogo, facilitador de grupos, professor, marido, amigo e eterno interessado pela vida.

\section{Considerações finais}

Não podemos considerar John Keith Wood um mero seguidor da abordagem centrada na pessoa, pois ele foi muito mais que isto. Participou ativamente da construção e da propagação das ideias da ACP, tanto no mun- do, quanto no Brasil, particularmente, de uma maneira muito especial. Ainda hoje, seu legado teórico e prático nos instiga a um pensamento ativo e vivo, permitindo-nos perceber como ele era um "crítico competente e equilibrado das iniciativas nesta área” (Wood, 2008, p. 166). Sua postura foi sempre a de um esclarecedor das delimitações e dos reais alcances da teoria e da prática da ACP, articulando e explicando o desenvolvimento das suas ideias, ao longo dos anos em que foi sendo desenvolvida e estruturada. Para ele, a prática da ACP apenas pode ser alcançada quando entendermos que ela requer um envolvimento que, além de cognitivo e profissional, precisa encontrar as raízes da essência da teoria nas suas próprias experiências de vida.

Conhecedoras da grandeza da vida e da obra de John Wood, e, também, cientes de sua sabedoria e acuidade sensitiva, bem como da sagacidade dos seus pensamentos e da sutileza da sua escrita, acreditamos que a sua contribuição para a abordagem centrada na pessoa no Brasil deve ser compreendida sem separar a sua vida de sua obra, já que este foi um dos seus maiores ensinamentos. Buscamos, ainda, fazer como ele fez, quando se referiu a Rogers e à ACP: clarificar, mas não encerrar a discussão, instigando uma busca sempre permanente e infindável das inúmeras possibilidades humanas, como lembra sua amiga querida Maureen O’Hara, no prefácio do livro Carl Rogers' Person-Centered Approach (Wood, 2008). A contribuição de John Keith Wood à abordagem centrada na pessoa no Brasil se evidencia e se mantém viva através da sua presença, nos grupos, nas aulas, nos livros, no coração de seus alunos e amigos, e no desempenho profissional competente e comprometido daqueles que aprenderam a ser com ele.

\section{Referências}

Amatuzzi, M. et al. (2002). A atitude de boa vontade e a abordagem centrada na pessoa. Estudos de Psicologia (Campinas), 19(2), p. 5-16.

Bandeira, E. P. (2012). Carl Rogers no Brasil. São Paulo: GRD Edições.

Cavalcante Junior, F. S. (2008). Abordagem Centrada na Pessoa. Mal Estar e Subjetividade (Unifor), 8(2), p. 529-535.

Fonseca, A. H. L. da (1983). Instituição, poder e vida ou da transação fascinada com a vida. In: Wood, J. K. (1983). Em busca de vida: Da terapia Centrada no Cliente à Abordagem Centrada na Pessoa (p. 139-183). São Paulo: Summus

Fonseca, A. H. L. da (2012). John. Consultado em 14 de dezembro de 2012 através de https://sites.google.com/site/ eksistenciaescola/eksistencia/john-2.

Gomes, W. B., Holanda, A. F., Gauer, G. (2004). História das Abordagens Humanistas em Psicologia no Brasil. In: Massimi, M. História da Psicologia no Brasil no Século XX (p. 105-129). São Paulo: EPU. 
Moreira, V. (2009). Clínica Humanista-Fenomenológica: estudos em psicoterapia e psicopatologia crítica. São Paulo: Annablume.

Moreira, V. (2010a). Revisitando as fases da abordagem centrada na pessoa. Estudos de Psicologia (Campinas), 27(4), p. 537-544.

Moreira, V. (2010b). Convergências e divergências entre as psicoterapias de Carl Rogers e Frederick Perls. Revista do NUFEN (Belém), 2(1), p. 20-50.

O’Hara. M (2008). Prefácio. In: Wood, J. K. (2008). Carl Rogers' Person-Centered Approach: Toward na understangin of its implications (p. iii-viii). UK: PCCS Books.

Rogers, C. (2001). Tornar-se Pessoa. São Paulo: Livraria Martins Fontes (Original publicado em 1961).

Wood, J. K. (1983). Em busca de vida: Da terapia Centrada no Cliente à Abordagem Centrada na Pessoa. São Paulo: Summus.

Wood, J. K. (1985). Vestígios de Espanto: Notas de Fim de Semana de um Psicólogo. São Paulo: Ágora.

Wood, J. K. (2008a). Abordagem Centrada na Pessoa (4 $\left.{ }^{\mathrm{a}} \mathrm{ed}\right)$. Vitória: EDUFES.

Wood, J. K. (2008b). Carl Rogers' Person-Centered Approach: Toward na understangin of its implications. UK: PCCS Books.

Virginia Moreira - Psicoterapeuta, Doutora em Psicologia Clínica pela Pontifícia Universidade Católica de São Paulo e Pós-Doutora em Antropologia Médica pela Harvard University. É Professora Titular da Universidade de Fortaleza e Affiliated Faculty da Harvard Medical School. Endereço Institucional: APHETO - Laboratório de Psicopatologia e Psicoterapia Humanista Fenomenológica Crítica. Programa de Pós-Graduação em Psicologia, Universidade de Fortaleza. Av. Washington Soares, 1321 (Fortaleza, CE). E-mail: virginiamoreira@unifor.br

Liane Bastos Landim - Psicoterapeuta, Mestranda em Psicologia Clínica pela Universidade de Fortaleza, Especialista em Neuropsicologia pela Unichristus. Atualmente é Residente no Programa de Residência Multiprofissional em Neurologia e Neurocirurgia no Hospital São Paulo pela Universidade Federal de São Paulo. Endereço Institucional: Rua Napoleão de Barros, 715, Vila Clementino, São Paulo - SP. E-mail: lianebl@yahoo.com

Geórgia Silva Romcy - Psicóloga, Residente Integrada em Saúde, com ênfase em Saúde Mental, pela Escola de Saúde Pública do Ceará - RIS/ ESP. Tem formação em Psicoterapia Fenomenológica-Existencial, Gestalt-terapia e Abordagem Rogeriana pela Escola Experimental de Psicologia e Psicoterapia Fenomenológico Existencial. E-mail: g.romcy@hotmail.com

Recebido em 01.04 .2013

Primeira Decisão Editorial em 21.07.2013 Segunda Edição Editorial em 28.08.2013 Aceito em 25.09.13 